\title{
Clinical Study \\ McGrath Video Laryngoscope May Take a Longer Intubation Time Than Macintosh Laryngoscope
}

\author{
Prerana N. Shah and Kaveri Das \\ Department of Anaesthesiology, Seth G. S. Medical College \& KEM Hospital, Parel, Mumbai, Maharashtra 400012, India \\ Correspondence should be addressed to Prerana N. Shah; pps@kem.edu
}

Received 1 August 2015; Revised 27 October 2015; Accepted 8 November 2015

Academic Editor: Young-Chang P. Arai

Copyright ( 2015 P. N. Shah and K. Das. This is an open access article distributed under the Creative Commons Attribution License, which permits unrestricted use, distribution, and reproduction in any medium, provided the original work is properly cited.

Background. Video laryngoscopes provide better view and can improve ease of intubation compared with standard laryngoscopes. Methods. A prospective randomized study was done on 60 patients, 18 to 65 years old, comparing McGrath video laryngoscope and Macintosh laryngoscope. The aim was to compare the ease, efficacy, and usability of them during routine airway management. The primary endpoint was duration of intubation and the secondary endpoints were Cormack and Lehane grade of laryngoscopic view, number of intubation attempts, and incidence of complications. Results. There was an increase in total duration of intubation with McGrath video laryngoscope with $42.9 \pm 19.5$ seconds compared to Macintosh laryngoscope with $17.9 \pm 4.6$ seconds. In Macintosh group, $73.3 \%$ had grade I, $20 \%$ had grade II, and 6.7\% had grade III Cormack Lehane view, while in McGrath group, $83.3 \%$ had grade I, $13.3 \%$ had grade II, and 3.3\% had grade III. In McGrath group, 6 patients (20\%) required more than 120 seconds to get intubated and only $73.3 \%$ were intubated in 1 attempt, while patients in Macintosh group had $100 \%$ successful intubation in 1 attempt. Pharyngeal trauma was seen with McGrath videolaryngoscopy. Conclusion. Duration of laryngoscopy, intubation, and total duration of intubation were significantly higher in McGrath group than in Macintosh group. McGrath group required a higher number of intubation attempts.

\section{Introduction}

Difficulty with tracheal intubation, especially in patients with unanticipated difficult airway, remains a frequent cause of anaesthesia related morbidity and mortality. Tracheal intubation can be attempted if laryngeal structures especially the cords are distinctly seen. It is usually done using laryngoscopes with different types of blades, namely, Macintosh, Miller, McCoy, and so forth. Laryngoscopes are devices typically consisting of a blade attached to a handle with a light source that allows examination of the upper airway through the mouth, often for the purposes of intubation.

New video laryngoscopes like McGrath, Storz, and so forth may help in intubation by giving a better view of the airway or improve intubation success by reducing the number of attempts of intubation and thereby decrease stress related to intubation [1]. The McGrath video laryngoscope is a videobased system for tracheal intubation which uses a video camera embedded into a "camera stick" [2]. The resulting video image is displayed on a small colour liquid crystal display (LCD) which is attached to the handle of the device [3]. The unit is used in much the same manner as an ordinary laryngoscope with the exception that once it has been introduced into the mouth by a few centimetres, one's attention should be directed to the LCD display. Thus, it helps to have a better view of the glottis and makes intubation easier by better manipulation of the tube through the larynx [2]. The aim of our study was to compare the ease, efficacy, and the usability of the McGrath video laryngoscope with those of standard Macintosh laryngoscope during routine airway management. The primary endpoint was duration of intubation [4] and the secondary endpoints were Cormack and Lehane grade of laryngoscopic view, number of intubation attempts (Table 3), and incidence of complications (Table 4) like lip trauma, teeth trauma, and pharyngeal trauma. 


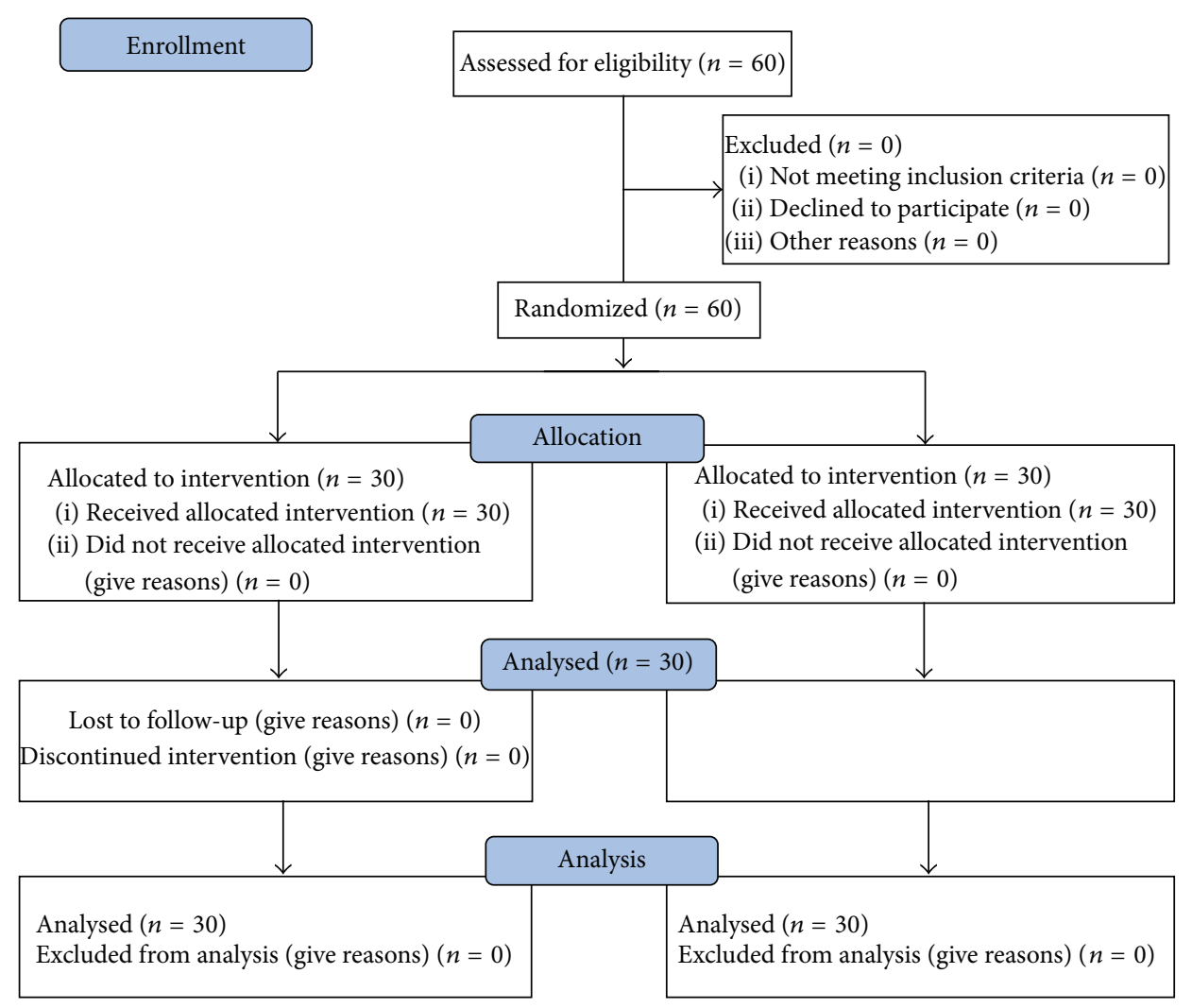

FIgURE 1: CONSORT 2010 flow diagram.

\section{Material and Methods}

The study was approved by the Ethics Committee for Research on Human Subjects, Seth G. S. Medical College \& KEM Hospital, Parel, Mumbai 400012 (address: Department of Pharmacology \& Therapeutics, 1st Floor, College Building, Seth G. S. Medical College \& KEM Hospital, Parel, Mumbai 400012) (Chairperson: Dr. Kamal Hazari, on 28 December 2011) (Ethical Committee EC/156/2011).

This study was conducted with written informed consent from the study subjects.

The prospective study was done in the age group 18 to 65 years undergoing elective surgical procedures needing general anaesthesia and allocated randomly using sealed envelope technique to undergo laryngoscopy using either McGrath video laryngoscope or Macintosh laryngoscope. From previous studies done by Walker et al. [5], the difference in intubation time in two groups was 17 seconds with standard deviation of 19 seconds. Assuming alpha of $5 \%$ and power of study set at $90 \%$, the sample size obtained was 26 per group. Accounting for dropouts final sample size was 30 per group (Figure 1).

Standard general anaesthesia technique using agents like Midazolam $0.02 \mathrm{mg} / \mathrm{kg}$, Pentazocine $0.6 \mathrm{mg} / \mathrm{kg}$, Propofol $2 \mathrm{mg} / \mathrm{kg}$, and Rocuronium $1 \mathrm{mg} / \mathrm{kg}$ muscle was used. Patients refusing to consent for study and patients intubated prior to surgery were excluded from the study. After achieving muscle relaxation, laryngoscopy was done by the same anaesthesiologist who was familiar with both types of laryngoscopes and had experience of at least 50 intubations with McGrath laryngoscope. Either McGrath video laryngoscope or Macintosh laryngoscope was used followed by tracheal intubation using suitable size endotracheal tube. In Macintosh laryngoscopy, intubation was done by direct visualization of the larynx [5]. In McGrath laryngoscopy, after the scope was introduced a few $\mathrm{cm}$ into the mouth, attention was shifted to the LCD screen attached to the scope for viewing the glottis. Once the glottis was visible, an appropriate sized endotracheal tube was guided with the help of view seen on the LCD screen. The number of attempts needed was noted.

Total duration of intubation ( $T$ ) was sum of $T 1$ and $T 2$ where $T 1$ was duration of laryngoscopy and $T 2$ was duration of intubation.

For McGrath videolaryngoscopy, the time taken from removal of face mask and insertion of laryngoscope blade between the teeth to indirect view of the glottis seen on the LCD screen was T1, while for Macintosh laryngoscopy, it was the time taken from removal of face mask and insertion of laryngoscope blade between the teeth to visualization of vocal cords and noting the Cormack and Lehane grading.

For McGrath videolaryngoscopy, the time taken from indirect view of the vocal cords seen on the LCD screen and passing the endotracheal tube in the trachea to confirmation 
TABLE 1: Duration of laryngoscopy and intubation.

\begin{tabular}{lccc}
\hline Group (mean \pm SD) & Macintosh & McGrath & $P$ value \\
\hline $\begin{array}{l}\text { Duration of } \\
\text { laryngoscopy (T1) } \\
\text { (seconds) }\end{array}$ & $9.3 \pm 3.33$ & $15.6 \pm 6.05$ & 0.0001 \\
\hline $\begin{array}{l}\text { Duration of } \\
\text { intubation (T2) } \\
\text { (seconds) }\end{array}$ & $8.6 \pm 2.7$ & $28.0 \pm 18.5$ & 0.0001 \\
\hline $\begin{array}{l}\text { Total duration of } \\
\text { intubation }(T)\end{array}$ & $17.9 \pm 4.6$ & $42.9 \pm 19.5$ & 0.0001 \\
$(T 1+T 2)($ seconds) & & & \\
\hline
\end{tabular}

of its tracheal placement was $T 2$. For Macintosh laryngoscope, the time taken from visualization of vocal cords and passing the endotracheal tube in the trachea to confirmation of its tracheal placement was $T 2$.

Cormack and Lehane grade of laryngoscopic view [6] and number of intubation attempts were noted. When tracheal intubation failed at the first attempt but succeeded at the second attempt, the sum of the times taken for the first time and the successful attempt was noted. Failure to intubate was considered if there was oesophageal intubation, if there was inability to place tracheal tube into the trachea within 120 seconds, and if more than three attempts were required. Incidence of complications like trauma to lips, pharynx, and teeth was noted and appropriately managed.

Student's $t$-test was used for between-group comparisons. Categorical data was compared using Chi-square test or Fisher's exact test.

\section{Results}

The demographic data with respect to age, gender, weight, height, and ASA grading was comparable. Both Macintosh group and McGrath group had 28 patients (93.3\%) belonging to Mallampati grade I and 2 patients (6.67\%) belonging to grade II.

$T 1$ was $9.33 \pm 3.33$ seconds in Macintosh group and 15.6 \pm 6.05 seconds in McGrath group. T2 was $8.6 \pm 2.7$ seconds in Macintosh group and 28.0 \pm 18.5 seconds in McGrath group required. Both $T 1$ and $T 2$ were statistically significant using unpaired $t$-test. Total duration of intubation $(T=T 1+T 2)$ in Macintosh group was $17.9 \pm 4.6$ seconds and for McGrath group it was $42.9 \pm 19.5$ seconds. This is shown in Table 1 .

In Macintosh group, $73.3 \%$ had grade I, $20 \%$ had grade II, and $6.7 \%$ had grade III Cormack Lehane view, while in McGrath group, $83.3 \%$ had grade I, $13.3 \%$ had grade II, and $3.3 \%$ had grade III. This was not significant using Chi-square test which was applied and shown in Table 2.

All patients in Macintosh group were intubated in the first attempt. In McGrath group, 22 patients (73.3\%) were intubated in 1 attempt, 2 patients (6.6\%) in 2 attempts, and 6 patients (20\%) in 3 attempts. This was statistically significant using Pearson Chi-square test. McGrath group showed successful intubation of 24 patients (80\%) with 6 patients (20\%) requiring more than 120 seconds to intubate which
TABLE 2: Cormack Lehane grade of view.

\begin{tabular}{lcccc}
\hline & Grade & Macintosh & McGrath & $P$ value \\
\hline & 1 & $22(73.3 \%)$ & $25(83.3 \%)$ & \\
Cormack Lehane & 2 & $6(20 \%)$ & $4(13.3 \%)$ & 0.629 \\
grade of view (\%) & 3 & $2(6.67 \%)$ & $1(3.3 \%)$ & \\
& 4 & $0(0 \%)$ & $0(0 \%)$ & \\
\hline
\end{tabular}

TABLE 3: Intubation attempts.

\begin{tabular}{lcccc}
\hline & Attempts & Macintosh & McGrath & $P$ value \\
\hline Number of intubation & 1 & $30(100 \%)$ & $22(73.3 \%)$ & \\
attempts \% & 2 & $0(0 \%)$ & $2(6.6 \%)$ & 0.009 \\
& 3 & $0(0 \%)$ & $6(20 \%)$ & \\
\hline Failure to intubate & & $0(0 \%)$ & $6(20 \%)$ & 0.024 \\
\hline
\end{tabular}

TABle 4: Complications.

\begin{tabular}{lcccc}
\hline \multirow{2}{*}{ Complications } & \multicolumn{2}{c}{ Macintosh } & \multicolumn{2}{c}{ McGrath } \\
& Number & $(\%)$ & Number & $(\%)$ \\
\hline Lip trauma (\%) & 0 & $(0 \%)$ & 0 & $(0 \%)$ \\
Teeth trauma (\%) & 0 & $(0 \%)$ & 0 & $(0 \%)$ \\
Pharyngeal trauma (\%) & 0 & $(0 \%)$ & 3 & $(10 \%)$ \\
\hline
\end{tabular}

was considered as intubation failure. This was statistically significant using Fisher's exact test.

Complications like pharyngeal trauma were slightly more in McGrath videolaryngoscopy than in Macintosh. There were no cases of lip or teeth trauma.

\section{Discussion}

Direct laryngoscopy using Macintosh laryngoscope has been used for laryngoscopy and intubation since 1943. Video laryngoscopes provide better laryngoscopic view on a video monitor and can hence potentially improve ease of intubation. In this study of 60 patients, intubating condition comparing the ease, efficacy, and the usability of the McGrath video laryngoscope with those of standard Macintosh during routine airway management was done.

Our study had no significant differences in Cormack and Lehane grading. Laryngoscopy and intubation time required in our study was less in Macintosh group. The number of attempts required to intubate was more in McGrath group than Macintosh group. Haemodynamics like pulse, blood pressure, and oxygen saturation were well maintained and were comparable in both groups.

Duration for laryngoscopy and intubation in our study was comparable with the various studies done by Shippey et al. [3], Walker et al. [5], Piepho et al. [7], and Taylor et al. [8]. Shippey et al. found that the median time to intubate the trachea with the McGrath video laryngoscope by experienced anaesthetists was 24.7 seconds [3] and Walker et al. [5] 
found a median intubation time of 47 seconds with inexperienced anaesthetic trainees. The mean time to intubate using the McGrath video laryngoscope by paramedics in the study made by Piepho et al. [7] was 48.2 seconds whereas in the study made by Taylor et al. it was 37.2 seconds [8]. In our study, second-year trainee did all the intubations. The increased duration of laryngoscopy and intubation in our study can be attributed to the fact that the video laryngoscope is new and was used by second-year trainee, thus probably requiring a greater learning curve, whereas the Macintosh laryngoscope was being used routinely. However, the study done by Taylor et al. [8] showed that McGrath video laryngoscope had better glottic view with more successful intubation than Macintosh laryngoscope when used in patients in simulated difficult airway requiring manual in-line stabilization. However, studies done by Noppens et al. [9], Piepho et al. [7], and Taylor et al. [8] showed that glottis view was better in McGrath video laryngoscope. The higher number of attempts required to intubate in McGrath group was also comparable to the study done by Walker et al. [5]. Piepho et al. [7] showed that McGrath video laryngoscope had similar rates of successful intubation like in Macintosh. Noppens et al. [9] showed that they had more successful intubation with McGrath video laryngoscope than Macintosh. Although video laryngoscopes provide a good view of the larynx, they may not guarantee an easy tracheal intubation and may prolong the time required for successful intubation [3,9], as seen in our study. While the angle of the McGrath and other video laryngoscope blades relative to the axis of the trachea improves the indirect view of the laryngeal inlet, it is necessary to redirect the tracheal tube more anteriorly, which can make it more difficult to achieve successful intubation of the trachea. It is also often necessary to bend the styletted tracheal tube to a greater degree than with direct vision laryngoscopes, which can hinder stylet removal and increase the time of intubation [8].

In spite of prolonged duration of intubation in McGrath group, hemodynamic changes were comparable to those in Macintosh group and were not statistically significant.

Complications like pharyngeal trauma were also slightly more with McGrath than Macintosh which can be explained by the nonfamiliarity of the video laryngoscope. This could also be attributed to difference in vision. While Macintosh provided a direct vision of the interior of the oropharynx and larynx, the McGrath video laryngoscope showed an indirect view on the display and the hand-eye coordination for firsttime users could lead to trauma. Thus, it was seen that demographic characteristics, view of larynx, and haemodynamic response and complications were comparable between the two groups. But duration of laryngoscopy, intubation, and total duration of intubation were significantly higher in McGrath group than in Macintosh group. Also, McGrath group required a higher number of intubation attempts. However, videolaryngoscopy gives a display that can be seen by others and can be used for teaching especially to novices. The limitation of the study was that the study was done by a single anaesthesiologist with a relatively more experience with Macintosh than with McGrath.

\section{Conclusion}

Although there was no significant difference in Cormack Lehane grade of view or haemodynamic response like pulse rate, blood pressure, oxygen saturation, and incidence of complications in both groups, McGrath video laryngoscope needed longer time and more attempts as compared to Macintosh laryngoscope.

\section{Disclosure}

All the authors attest the fact that they have read the paper, attest the validity and legitimacy of the data and its interpretation, and agree on its publication.

\section{Conflict of Interests}

The authors report no conflict of interests regarding the publication of this paper.

\section{Authors' Contribution}

Prerana N. Shah was responsible for conducting the study, study design, patient recruitment, data collection, data analysis, and writing. Kaveri Das helped design and conduct the study and helped in patient recruitment, data collection, data analysis, and writing.

\section{References}

[1] B. Shippey, D. Ray, and D. McKeown, "Case series: the McGrath videolaryngoscope-an initial clinical evaluation," Canadian Journal of Anesthesia, vol. 54, no. 4, pp. 307-313, 2007.

[2] "Aircraft Medical, McGrath Brochure," 2014, http://www.aircraftmedical.com/index.php?option=com_content\&view= article\&id=263\&Itemid=180, http://www.aircraftmedical.com.

[3] B. Shippey, D. Ray, and D. McKeown, "Use of the McGrath video laryngoscope in the management of difficult and failed tracheal intubation," British Journal of Anaesthesia, vol. 100, no. 1, pp. 116-119, 2008.

[4] D. C. Ray, C. Billington, P. K. Kearns et al., "A comparison of McGrath and Macintosh laryngoscopes in novice users: a manikin study," Anaesthesia, vol. 64, no. 11, pp. 1207-1210, 2009.

[5] L. Walker, W. Brampton, M. Halai et al., "Randomized controlled trial of intubation with the McGrath Series 5 video laryngoscope by inexperienced anaesthetists," British Journal of Anaesthesia, vol. 103, no. 3, pp. 440-445, 2009.

[6] R. S. Cormack and J. Lehane, "Difficult tracheal intubation in obstetrics," Anaesthesia, vol. 39, no. 11, pp. 1105-1111, 1984.

[7] T. Piepho, K. Weinert, F. M. Heid, C. Werner, and R. R. Noppens, "Comparison of the McGrath Series 5 and GlideScope Ranger with the Macintosh laryngoscope by paramedics," Scandinavian Journal of Trauma, Resuscitation and Emergency Medicine, vol. 19, no. 1, article 4, 2011.

[8] A. M. Taylor, M. Peck, S. Launcelott et al., "The McGrath Series 5 Series 5 videolaryngoscope vs the Macintosh laryngoscope: a randomised, controlled trial in patients with a simulated difficult airway," Anaesthesia, vol. 68, no. 2, pp. 142-147, 2013.

[9] R. R. Noppens, S. Möbus, F. Heid, I. Schmidtmann, C. Werner, and T. Piepho, "Evaluation of the McGrath series 5 videolaryngoscope after failed direct laryngoscopy," Anaesthesia, vol. 65, no. 7, pp. 716-720, 2010. 


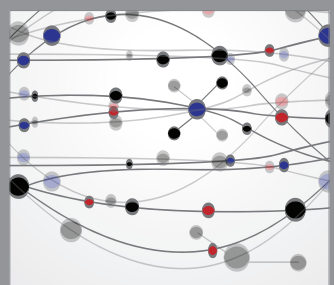

The Scientific World Journal
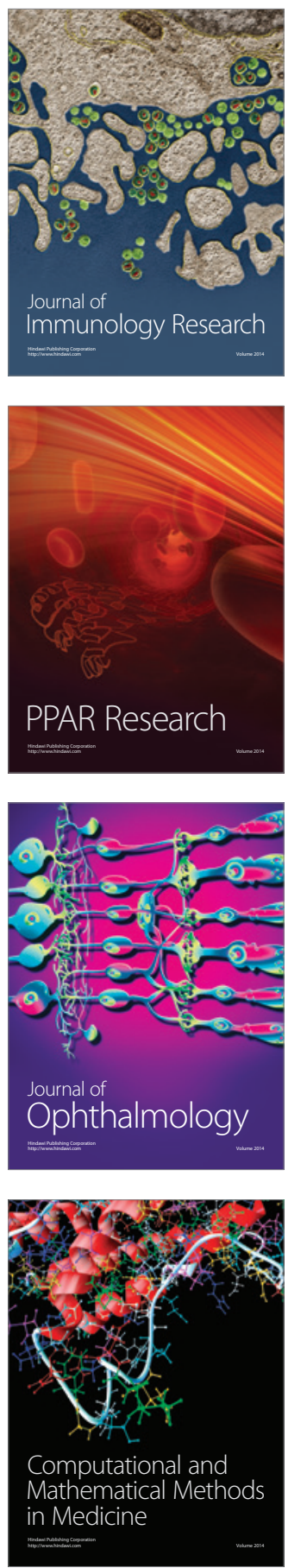

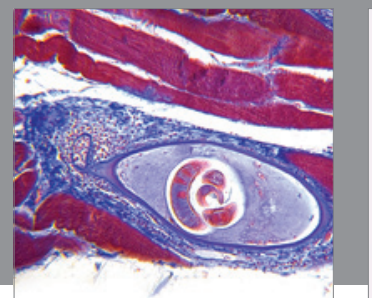

Gastroenterology

Research and Practice
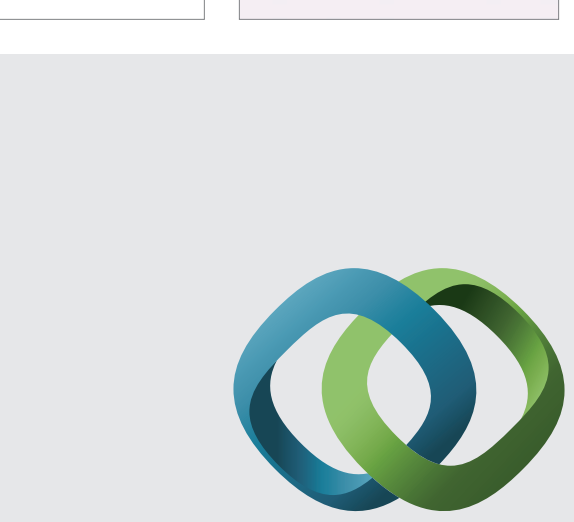

\section{Hindawi}

Submit your manuscripts at

http://www.hindawi.com
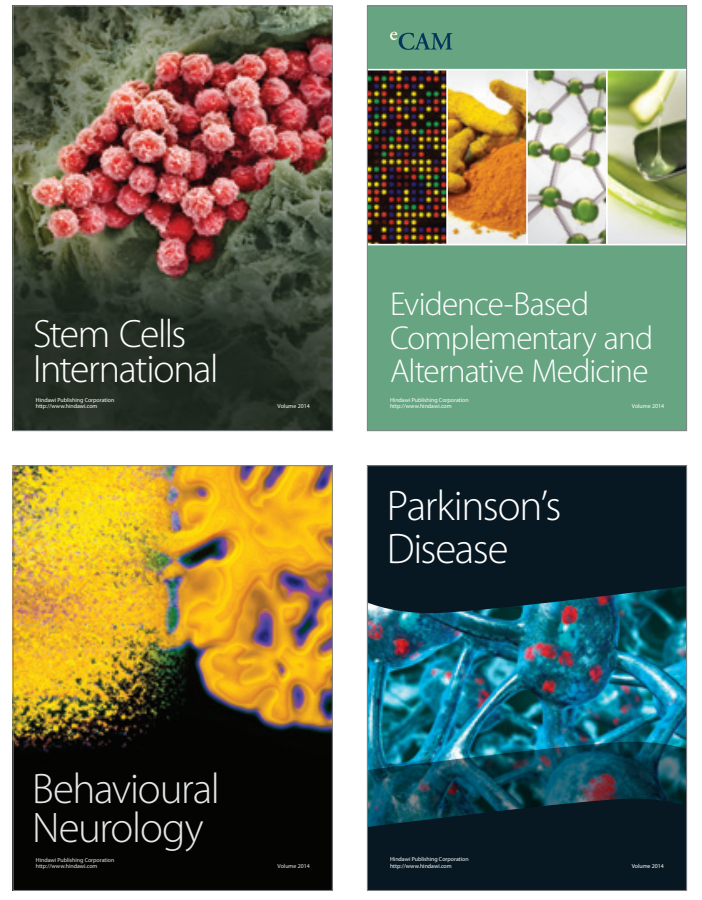
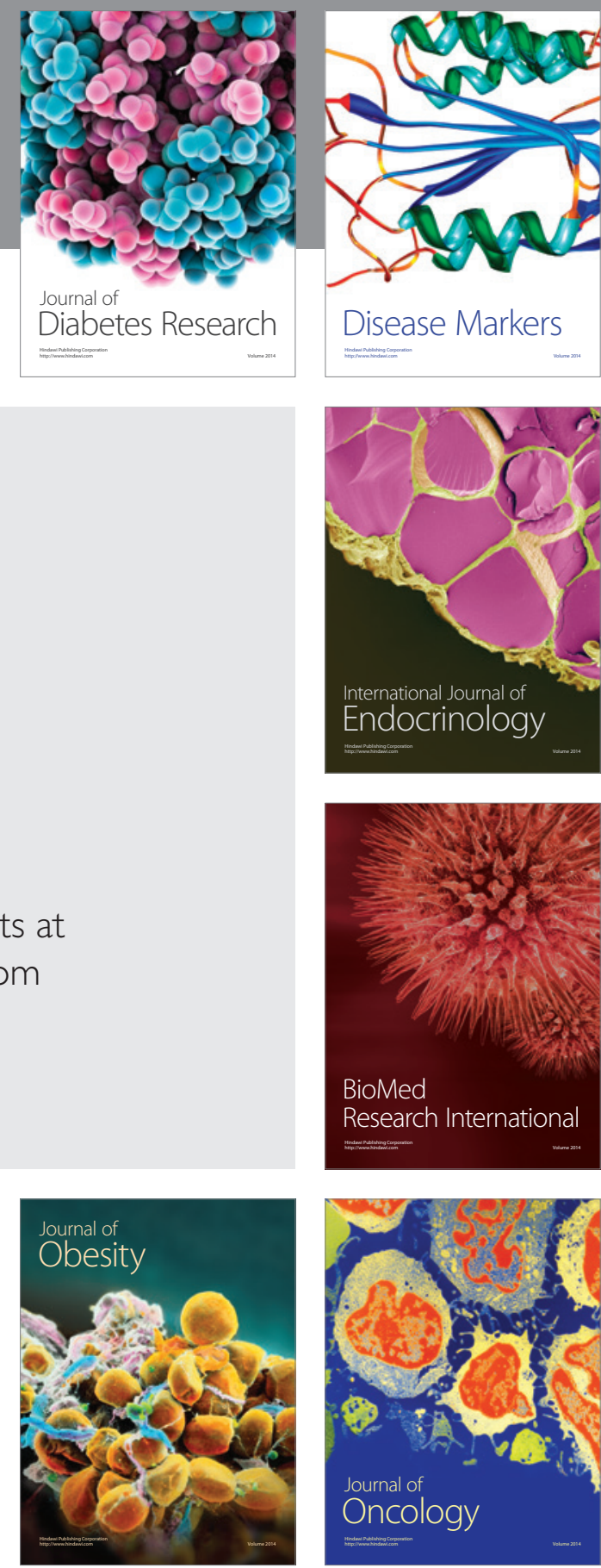

Disease Markers
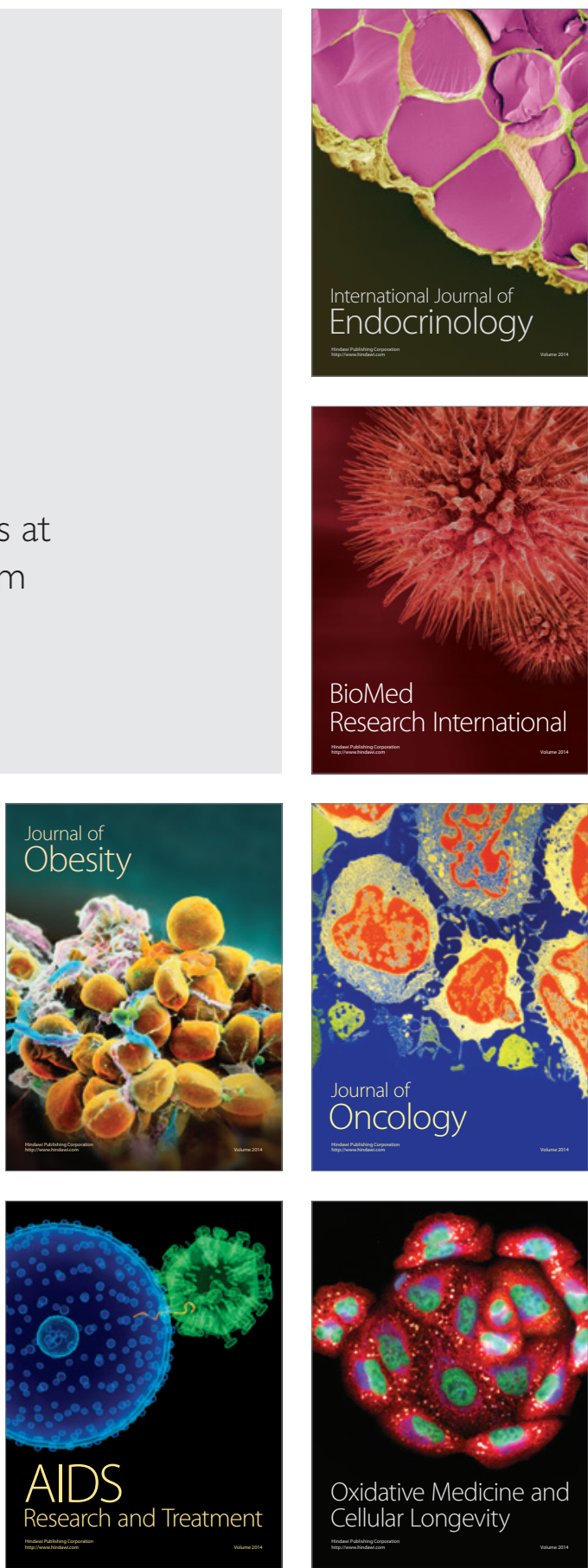